\title{
REARING OF FIELD COLLECTED LARVAE OF THE MAHOGANY SHOOT BORER, Hypsipyla robusta (MOORE) ON AN ARTIFICIAL DIET: A PRELIMINARY STUDY
}

\author{
Rizana M Mahroof Jayanthi P Edirisinghe and Caroline Hauxwell* \\ "Department of Zoology, University of Peradeniya, Peradeniya \\ " Institute of Ecology and Resource Management, University of Edinburgh
}

Hypsipyla robusta (Morre) (Lepidoptera: Pyralidae) is an important pest of mahogany, Swietenia macrophylla (King) in Sri Lanka and world over. Larval attack at an early stage of growth, leads to branching which reduces the quality and value of timber, significantly. Work is in progress to study the effect of shade on the growth and development of mahogany and attack by the shoot borer. This paper presents aspects of development of shoot borer larvae reared on an artificial diet, as well as field information related to damage and parasitism. Larvae collected from two field sites at fortnight intervals were reared in the laboratory on an artificial diet at $27-32^{\circ} \mathrm{C}$. Development of field collected larvae were followed until the emergence of adults, during which duration of the developmental stages, adult sex ratio, parasitism level and mortality were recorded. Measurement of head capsule widths of larvae collected and their location on the shoot, was also made. A total of 774 larvae were collected and reared during the study, out of which 120 Hypsipyla adults emerged giving a male: female sex ratio of $1: 8$. Nearly $40 \%$ of the field collected larvae were parasitized by Cotesia app. (Hymenoptera: Braconidae). Head capsule measurements indicated five larval instars that were found to infest different parts of the growing shoot. Duration of development of larvae differed depending on whether they were parasitized or not. Several problems encountered during rearing are discussed.

Proceedings of the Third Annual Forestry Symposium 1997, of the Department of Forestry and Environmental Science, University of Sri Jayewardenepura, Sri Lanka 